\title{
LANGUAGE TRANSFER IN LEARNER LANGUAGE
}

\author{
Warsono \\ State University of Semarang \\ titaniafitriani@gmail.com
}

\begin{abstract}
In using the foreign language they are learning, learners tend to use forms that deviate from the target language (TL) norms. The question that arises is whether these forms are the result of transfer or the result of some other causes; and if transfer does exist in learner language, whether it diminishes with the development of the learner TL achievement. This paper tries to find answers to these questions by (1) reviewing some related literature, and (2) looking at some data of learners' written production of Indonesian learners of English. The data were collected from the writings of the fifth semester students of the English Department (group A, representing low level of L2 achievement), and the final projects written by the English Department students (group B, representing high level of L2 achievement). In this paper, all forms that deviate from the TL norms were called errors, irrespective of whether they were, in fact, mistakes or real errors. The learners' errors were broadly classified into two classes: intralingual errors and interlingual errors, and it was the latter that became the focus of this study on the assumption that interlingual errors were caused by $L 1$ transfer. The results of data analysis showed that intralingual errors were slightly higher in group A than interlingual ones; but in group $B$ interlingual errors formed the majority of errors made by the learners (75\%). It can be concluded that L1 transfer does exist in the L2 of the Indonesian learners of English. The results also showed that L1 transfer does not diminish with the development of the L2 achievement. It is strongly suggested, therefore, that Indonesian English teachers anticipate the errors caused by L1 transfer and find ways to solve the problems.
\end{abstract}

Keywords: Error, mistake, learner language, language transfer.

\section{INTRODUCTION}

Foreign or second language (L2) learning has become a fashion in this modern world. Speaking only one language (a national language) is deemed inadequate in this modern era, particularly among educated people. An educated person has to be able to use and understand at least one more language, a second or foreign language, preferably one that is internationally understood, such as English, in order to be able to socially survive in the world that is becoming more and more transparent. 
Journal of English Education, Literature, and Culture

However, L2 learning is not that simple. For many people, L2 learning is a perpetual burden, something that cannot be overcome overnight. In their attempt to master the new language, there is always a tendency for them to revert to the habit of using their own native language (L1). Their efforts in mastering the new language are much hampered by the habit of using their earlier mastered language or languages. As a result, when learners produce the new language, their language production is filled with forms that deviate from the target language (TL) norms, often called errors or mistakes. The question that arises is: "Are these errors caused by L1 transfer, or are they caused by some other causes?" Another pestering question is: "Does L1 transfer, if any, diminish with the development the learner's level of TL mastery?"

This paper tries to answer these questions by (a) reviewing some related literature, and (b) analyzing written production of TL by students of English departments from two different universities, one a government university and one private university, referred to as students of group A, representing learners of lower level of TL mastery, and students of group B, representing learners of higher level of TL mastery. The next section contains a brief review of some related literature that can be used as a basis in answering the research questions, and also in order to clarify some terms that are used in this paper such as: error or mistake, transfer or interference.

The idea of language transfer goes back to the behaviourist era during the 1950 s and the 1960s. According to the behaviourist theories, the main impediment to learning was interference from prior knowledge (Ellis 1994: 299). In the case of language learning, the prior knowledge is the knowledge of the native language (L1) and perhaps some other earlier learned language before the learner undertakes the learning of the language concerned, called the target language (TL). The underlying idea of language transfer is the behaviourist belief that language learning involved 'habit formation', thus, in learning another language, the learner transfers the habit of using L1 into the habit using the target language.

According to the behaviourist theories of L2 learning, the degree of difficulty in L2 learning depends primarily on "the extent to which the target language pattern was similar to or different from a native language pattern" (Ellis 1994: 300). Forms that were identical in both L1 and L2 would facilitate 
Journal of English Education, Literature, and Culture

learning; the learner could just transfer the L1 form to the L2 through the socalled positive transfer. However, where forms were different between the two languages, learning difficulty would arise through the so-called negative transfer, often referred to as interference. This view entails the need, for pedagogical purposes, to carry out contrastive analysis (CA), contrasting the learner's L1 and the target language to find out points of similarities and points of differences between the two.

These behaviourist views about L2 learning were then challenged by Chomsky (1959) after he reviewed Skinner's theory of Verbal Behaviour. Chomsky believed that 'stimulus' and 'response' theory was true only of animal's behavior, but it cannot be applied to language behavior of human beings. Chomsky also rejected the idea of habit formation in language acquisition. He believed that language acquisition was not habit formation but rule formation and developmental in nature, affected by both internal and external factors. Later researchers also discredited the behaviourist views about language learning, particularly the idea of L1 transfer into L2 learning. Dulay and Burt (1974), in Richards (1974), seriously underestimated the role of L1 in L2 learning, as they found very few interference errors in their empirical study. Dulay and Burt were not the only researchers who refuted the behaviourist claims about L1 transfer. Krashen (1981) and others supported Dulay and Burt's statement that "it is the L2 system (the target language) rather than the L1 system (the native language) that guides the acquisition process."

More recently, however, the importance of transfer has again been acknowledged. Fauziati (2009: 121) states, "Native language transfer has become and will always be the concern of second language acquisition studies." Other researchers, (Liu 2013, Choroleeva 2013, Doughty and Long 2008, Gass and Selinker 1983) also believed that language transfer plays an important role in second or foreign language learning. Odlin (1993: 3-4) gave the following remark: "Despite the counterarguments ... there is a large and growing body of research that indicates that transfer is indeed a very important factor in second language acquisition."

Larsen-Freeman and Long (1991: 56) supported the view that L1 influence on L2 learning did occur. They stated, “... no one could deny that the L1 influenced L2 performance, so that we can often identify with some degree of 
Journal of English Education, Literature, and Culture assurance the native language of a foreign speaker ... ". They also added, "To be sure, SL (L2) learners still committed errors which could be traced to L1 interference ... “ Jack Richards (1971 in Ellis 1994)), labelled errors caused by L1 interference interlingual errors, and those that could not be traced back to L1 interference intralingual errors. In this paper, these two terms were used to classify the errors made by the subjects under investigation.

People's interest in language transfer led to studies of cross linguistic influence, which may also be called transfer analysis. Transfer analysis is an analytical tool (Fauziati 2009) which may be used to analyze learner's TL production which deviates from the TL norms. Fauziati (2009), quoting James (1990) further added that transfer analysis constitutes a sub discipline within error analysis which rests upon the assumption that certain deviances in learner production are the results of native language (NL) transfer.

Forms that deviate from the target language norms may or may not be called errors, depending on whether the learner consistently makes the same deviated form through a considerable period of time. If, for the same target language item, the learner sometimes uses the correct form and sometimes the wrong one, it is likely that the wrong form is caused by carelessness or sloppiness, in which case it is called a mistake. An error is caused by the learner's lack of knowledge of the target language norms. "It represents a lack of competence." (Ellis, 1994: 51). Ellis (1994) further stated, "A mistake occurs when learners fail to perform their competence."

Odlin (1993: 37) stated that in speech and writing, there are three types of errors that may be caused by the similarities and differences in the native and target languages: (1) substitutions, (2) calques, and (3) alterations of structures. "Substitutions involve a use of native language forms in the target language. ... Calques are errors that reflect very closely a native language structure." (Odlin 1993: 37). Alterations of structures can be seen in hypercorrections which are sometimes caused by overreactions to a particular influence from the native language. In this study, particular attention was paid to calques: errors that reflect the native language structure. 


\section{METHOD}

In trying to answer the two questions stated in the introduction of this paper, the first thing the writer did was reviewing some related literatures to see whether theoretically L1 transfer in L2 learning is a common phenomenon, and also to find out whether L1 transfer is more common among beginner learners than among more advanced learners. This having been done, then the data of the learners' L2 production were collected from two kinds of learners' written productions: 1) written compositions of the fifth semester students of English department of a state university in the form of hand-written paragraphs ranging in length from half a page to three-quarters of a page, folio size paper; 2) written productions of students of English who were writing their final projects in one of the private universities in Semarang, in the form of drafts of their final projects.

The data collected were qualitative in nature, as they were in the forms of words, phrases, or sentences that deviated from the TL norms. These learners' written productions were then analyzed using simple methods based on the division of errors proposed by Jack Richards (1971 in Ellis 1994), i.e. interlingual errors and intralingual errors. This paper's particular interest is in finding out whether L1 transfer exists in the language of the Indonesian learners of English.

The two groups of students from whom the data were collected were referred to as group A and group B. Group A consisted of 20 semester-five students of an English department of a state university in Semarang, representing the lower level of TL achievement; group B consisted of 5 English department students writing their final projects in a private university in Semarang, representing the higher level of TL achievement. The sources of data collected from group A were single paragraphs which ranged in length from half to three-quarters of a page of folio-size paper. The sources of data collected from group B were final project drafts which ranged in length from 40 to 50 pages, type-written, double-spaced. Since identifying all the errors from all the 40 to 50 pages of the final project drafts was time consuming and was considered unnecessary as sampling the errors can overcome the problem, only about $20 \%$ of the number of pages in each draft were used as the sources of data collection. 
In this study, some wrong forms could be directly called errors for certain, as they occurred repeatedly in the same paper; others, however, occurred only once in the whole learner's paper which made it difficult to decide whether the wrong form is an error or a mistake. This problem arose because the data were collected cross-sectionally, in one period of time. Unless data collection is done longitudinally, wrong forms that occur only once in the learner's one shot production cannot be determined whether they are errors or mistakes. In this study, however, deviated forms that occurred only once in the learners' written production were considered as errors to overcome the problem of indecision. The data collected from the two groups can be seen in the following tables.

Table 1 Data collected from group A

\begin{tabular}{|c|c|c|c|}
\hline $\begin{array}{l}\text { Student } \\
\text { No. }\end{array}$ & Number of errors & Interlingual errors & Intralingual errors \\
\hline 1 & 10 & 4 & 6 \\
\hline 2 & 14 & 8 & 6 \\
\hline 3 & 6 & 1 & 5 \\
\hline 4 & 3 & 3 & 0 \\
\hline 5 & 12 & 5 & 7 \\
\hline 6 & 11 & 4 & 7 \\
\hline 7 & 7 & 2 & 5 \\
\hline 8 & 7 & 2 & 5 \\
\hline 9 & 2 & 1 & 1 \\
\hline 10 & 6 & 2 & 4 \\
\hline 11 & 5 & 3 & 2 \\
\hline 12 & 8 & 5 & 3 \\
\hline 13 & 8 & 3 & 5 \\
\hline 14 & 5 & 3 & 2 \\
\hline 15 & 4 & 2 & 2 \\
\hline 16 & 5 & 4 & 1 \\
\hline 17 & 3 & 2 & 1 \\
\hline
\end{tabular}


Journal of English Education, Literature, and Culture

\begin{tabular}{cccc}
\hline 18 & 5 & 2 & 3 \\
\hline 19 & 8 & 3 & 5 \\
\hline 20 & 10 & 3 & 7 \\
\hline Total & 139 & 62 & 77 \\
\hline
\end{tabular}

The table above shows that less than $50 \%$ of the total errors made by this group of students could be categorized as interlingual errors, the ones that can be traced to the L1 transfer. More than $50 \%$ of the total errors, on the other hand, were not traceable to the $\mathrm{L} 1$ transfer, hence they were categorized as intralingual errors. Errors categorized as interlingual ones included errors in:

1. Absence of articles

2. Word order (using L1 word order)

3. Absence of - s ending to show plural

4. Indonesian sentences worded in English (Indonesian way of thinking literally translated into English)

Table 2 Data collected from group B

\begin{tabular}{cccc}
\hline $\begin{array}{c}\text { Student } \\
\text { No. }\end{array}$ & Number of errors & Interlingual errors & Intralingual errors \\
\hline 1 & 56 & 40 & 16 \\
\hline 2 & 60 & 49 & 11 \\
\hline 3 & 60 & 44 & 16 \\
\hline 4 & 63 & 58 & 5 \\
\hline 5 & 62 & 32 & 78 \\
\hline Total & 301 & 223 & \\
\hline
\end{tabular}

The data collected from group B shows that the majority of the errors, about $75 \%$, belong to interlingual ones. This contrasts with the data collected from students of group A, in which a larger proportion of the errors were intralingual. However, the two tables show that L1 transfer does exist among Indonesian learners of English, although not all errors were traceable to the L1 language system. Table 2 also answers the second question of the research: the higher level of TL achievement does not guarantee the reduction of the frequency of $\mathrm{L} 1$ transfer in the learner's production.

The reason for the big difference in the number of errors made by students of group B from those made by students of group A is, as has been mentioned earlier, that students of group A wrote only one paragraph each (i.e. 
Journal of English Education, Literature, and Culture the data were collected from 20 paragraphs), whereas students of group B wrote final projects, from each of which a few pages were used as the sources of data. There are two other things that need to be made clear in this study. First, recurring errors were considered as separate or different errors; for example, the absence of an article that occurred five times within one student's paper was considered as five different errors. Second, all forms that deviated from the target norms were considered as errors, including a deviated form that occurred only once in the data source. The latter policy was taken to overcome the problem of indecision because the data were collected cross-sectionally, not longitudinally.

\section{FINDINGS AND DISCUSSION}

The results of simple data analysis showed that there was a difference between the errors made by students of group A and those made by students of group B. Most of the errors made by students of group A belonged to intralingual errors, for which no traces of L1 transfer could be detected, whilst those that showed the traces of L1 transfer only formed less that $50 \%$ of the total errors. Errors made by students of group B, on the other hand, showed the opposite finding. The majority of the students' errors, about $75 \%$ of the total errors, resulted from the influence of L1 which, in this paper, is called L1 transfer.

Most of the errors made by students of group B were the absence of articles, both definite and indefinite. This kind of error was considered as L1 transfer because Indonesian has no equivalence of the English article, so the lack of this equivalence causes Indonesian learners of English to drop the use of article. The same thing was also true of the absence of the $-\mathrm{s}$ ending to show plural, which formed the second largest number of errors made by both groups of students. Indonesian does not have a special marker of plurality, i.e. plural nouns and singular nouns have the same form in Indonesian. This fact caused the students to ignore the use of -s ending to show plural in English.

Other kinds of errors were errors in word order, i.e. using Indonesian word order, and sentences reflecting Indonesian way of thinking, which were 
translated literally into English. In other words, they were Indonesian sentences but worded using English words. These kinds of errors were not large in number, but they form potential problems for Indonesian learners of English. Second or foreign language learners who still have not achieved a high level of mastery of the target language (TL) tend to think first in the L1 and then they translate their thinking into the TL. This is a common phenomenon that happens to second or foreign language learners, and it is the job of a teacher to make the learners aware of this fact and to find solution how to overcome this problem.

It has to be admitted that there are limitations to this study. First, the data of this study were collected cross-sectionally which caused difficulty in deciding whether deviated forms that occurred only once in the learner's written production could be called errors or not (in this study they were all called errors). Second, the learners' written productions which were used as the sources of data were not of equal length: single paragraphs for students of group A and several pages of final project drafts for students of group B. Third, recurring deviated forms were considered as separate errors in this study. These certainly formed the weaknesses of this study.

However, these weaknesses do not weaken the conclusion that L1 transfer does exist among Indonesian learners of English. Indonesian teachers of English will have noticed the same kinds of errors in their students' productions, both written and spoken: missing of the necessary articles, wrong word order, absence of plural -s ending, Indonesian sentences worded using English words. Therefore, in spite of the controversy about the importance of conducting contrastive analysis (CA), it is still necessary for Indonesian teachers of English to do it in order that they can anticipate the possible errors caused by L1 transfer in their students' L2 productions. Some of what may have been predicted as problems, as a result of CA, may not prove to be problems at all, but that does not matter. It is better than not making any prediction at all.

\section{CONCLUSIONS AND SUGGESTIONS}

The results of data analysis showed that there was a difference in the type of errors made by students of group A and those made by students of group 
Journal of English Education, Literature, and Culture

B. Among students of group A, representing students of lower level of L2 achievement, intralingual errors were slightly larger than interlingual errors. However, among students of group B, representing students of higher level of L2 achievement, interlingual errors formed the majority of errors.

This difference, however, does not affect the conclusion that L1 transfer does exist among Indonesian learners of English. The fact that interlingual errors formed the majority of errors made by students of group B showed that interlingual errors do not diminish with the development of L2 achievement. Thus, the final conclusions of the study are: 1) that L1 transfer exists among Indonesian learners of English; 2) that L1 transfer does not diminish with the development of the learners' L2 achievement. It is strongly suggested, therefore, that Indonesian teachers of English be familiar with CA and use it as a means of predicting the possible errors that could be made by their students in their L2 production. In this way, they will always be ready with the solution when errors do occur. 


\section{REFERENCES}

Chomsky, Noam. 1959. 'Review of "Verbal Behaviour” by B.F. Skinner'. Language 35: 26-58.

Choroleeva, Komelia. 2008. Language Transfer: Types of Linguistic Errors Committed by Francophones Learning English as a Second/Foreign Language http://www.hltmag.co.uk/oct09/mart02htm. (accessed on Nov. 5, 2013).

Doughty, Catherine J. and Michael H. Long. 2008. Cross-linguistic Influence. Published Online. (Accessed on Nov. 4, 2013)

Ellis, Rod. 1994. The Study of Second Language Acquisition. Oxford: Oxford University Press.

Fauziati, Endang. 2009. Readings on Applied Linguistics: A Handbook for Language Teacher and Teacher Researcher. Surakarta: Era Pustaka Utama. Gass, Susan and Larry Selinker (eds.). 1983. Language Transfer in Language Learning. Rowley, Mass.: Newbury House Publishers.

Krashen, S. 1981. Second Language Acquisition and Second Language Learning. Oxford: Pergamon.

Larsen-Freeman, Diane and Michael H. Long. 1992. An Introduction to Second Language Acquisition Research. London: Longman.

Liu, Shoozhong. 2003. Studies of Transfer in Second Language Acquisition. http://www.gxnu.edu.cn/Personal/szliu. (accessed on Nov.5, 2013)

Odlin, Terence. 1993. Language Transfer: Cross linguistic influence in language learning. Cambridge: Cambridge University Press.

Richards, J. (ed.) 1974. Error Analysis. London: Longman 